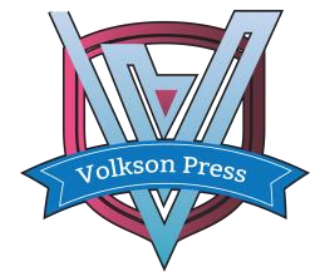

Contents List available at VOLKSON PRESS

Economics \& Management Innovations(EMI)

DOI : http://doi.org/10.26480/icemi.01.2017.88.89

\title{
Analysis of marketing strategy of innovative agricultural products
}

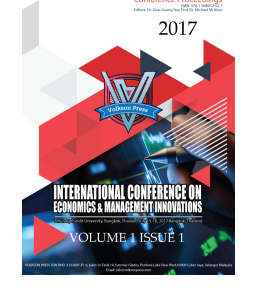

\author{
Yanping Chen \\ WUHAN DONGHU UNIVERSITY \\ 757088198@qq.com
}

This is an open access article distributed under the Creative Commons Attribution License, which permits unrestricted use, distribution, and reproduction in any medium, provided the original work is properly cited.

\section{ARTICLE DETAILS}

\section{Article History:}

Received 02 october 2017

Accepted 06 october 2017

Available online 11 october 2017

Keywords:

Strategy, Internet +, story

marketing,network marketing

\section{ABSTRACT}

Starting with the characteristics of consumer behavior of agricultural products, this paper analyzes the successful cases of network marketing of agricultural products in China, and puts forward the strategy innovation of network marketing of agricultural products.

\section{Marketing status of traditional agricultural products}

\subsection{Asymmetric information results in bumper harvest}

The large retail enterprises and agricultural products processing enterprises as the core to carry out, in this case, farmers rely on lagged market feedback information to determine what production does not produce what, so blindly follow the trend of the phenomenon of planting is very common, the final result is out of touch with the market demand of agricultural products, agricultural products unmarketable, high yield but difficult to harvest.

It is concluded that asymmetric information of production and marketing is the root cause of high yield and difficult harvest.Although as early as 2011, the Ministry of agriculture has set up rural information network platform, in order to provide product information collection, collation, analysis and dissemination services for farmers, however on the one hand, in practice, there are still some information release lag, farmers complain that information sharing does not have the production guidance is correct, lost the meaning of construction platform. On the other hand, for the use of information on the network platform, the quality of farmers also made certain requirements, this requirement includes the network of cognitive and practical network skills.

\subsection{Backward marketing}

The traditional marketing mode of agricultural products is mainly offline marketing. The specific operation is farmers in the harvest season of agricultural products lagged behind, do not take the initiative to find a buyer, but wait from wholesalers to buy home, and then through the layers of circulation. We believe that in this marketing model, the position of farmers in bargaining stage is no advantage, can only be the recipient of the price. In such a passive situation, it is difficult for farmers to obtain accurate market feedback information, product demand and market forecast. Will fall into the blind production situation once again .

\section{Innovative agricultural products marketing model analysis}

\subsection{Innovative marketing concept of agricultural products}

According to the definition of Baidu encyclopedia, "Internet plus" is the "Internet plus various traditional industries", but this is not a simple combination, but the use of information and communication technology and the Internet platform, so that the Internet and traditional industries depth of integration, to create a new ecological development.
First of all, the rapid popularization of mobile phones as a mobile terminal so that farmers access to the network opportunities and costs significantly reduced, then farmers can achieve timely access to user needs and product information possibilities. Secondly, China's large electricity supplier platform actively added agricultural products trading business, such as supermarket has fresh fruit business. The development of agricultural products electricity supplier, make traditional agricultural products marketing to new direction of development, so that farmers and the market to achieve seamless docking possible.

\subsection{Innovative agricultural product sales model}

In fact, the entity sales mode in the past the traditional line is already unable to meet the modern consumer diversification of consumer demand for agricultural products, only sales model innovation to faster and better services, interact with consumers to achieve. At this stage, to promote the "Internet $+"$ and the organic integration of agricultural products, agricultural products to achieve network marketing.

Network marketing of agricultural products refers to the sales of agricultural products in the process, into a comprehensive e-commerce system, the use of information technology, the demand and price of publication and collection, to network media, relying on agricultural production base and logistics distribution system for local agricultural products, enhance brand image, enhance customer relationship, improve customer service, develop the network of sales channels and expand sales.

\section{Successful network marketing case analysis - Chu Orange}

Chu orange, sweet with thin skin is named for Chu Shijian's inspirational legend, commercial brand "Yunguan orange". In November 5, 2012, Chu orange network first, 5 minutes to sell 800 boxes, 20 tons in 3 and a half days sold out, eventually selling 200 tons. Hot online marketing attracted widespread concern, and promote further growth of the traditional channel sales.

\subsection{The origin of the 3.1 "Chu orange"}

Chu Shijian, as one of the important areas of the role of tobacco in 80s, creating a first in Asia, the world's fifth group companies, he created 140 billion yuan of tax, in 1999 for the country, because of corruption and the crime of huge unidentified property was sentenced to life imprisonment and deprivation of political rights for life.

In May 2001, Chu Shijian suffering from severe diabetes medical parole. 
After a period of hardship, 2400 acres of barren hills turned into orange orchards. From the beginning of the Guaguo to Kunming in Yunnan No one shows any interest in Chu orange described after high streets and back lanes, wind and rain, in 2012, it is business like a raging fire, tenth years is Chu orange planting, and Chu Shijian have been living network cooperation, starting from the electricity supplier of the Road, hit. By 2015, the 88 year old Chu Shijian battles electricity supplier entrepreneurship, set up "Chu orange flagship store in Tmall, joined the Alibaba group star plan.

\subsection{Analysis of Chu orange network marketing strategy}

\section{(1) Accurate target customers}

The market generally of navel orange in the general price of $\$ 4-7$ per kilogram, while the price of Chu orange in the catty $15-16$ yuan, with the United States and Australia imported imported navel orange navel orange is the same price. Usually the price is fixed and the market becomes smaller. Chu orange is in the face of high-end consumer groups, have a higher than average standard for quality of life, consumption is not susceptible to the impact of price fluctuations. This kind of high-end consumer groups, mostly well-educated, accept the information channels more diversified, more powerful ability to accept new things, in addition to their consumption of the product itself, but also is affected by Chu orange founder Chu Shijian personal legend.

It is Chu orange brand personality and marketing success story, with the help of network promotion, can still achieve good sales in high price.

\section{(2) Standardization of product production}

Chu orange on standardized production of agricultural products, the development of the fine line, to product differentiation. The Chu orange base has more than and 300 employees, unified allocation of production materials, screening equipment with advanced fruit, fruit of washing, drying, classification, finally loading, ensure the quality of each fruit.

\section{(3) Combination of word of mouth and story marketing}

In recent years, the success of Chu orange have been used as a model of marketing and network marketing success story has been widely circulated. On the other hand, word-of-mouth marketing micro-blog big V, also makes Chu orange inspirational effect continuous fermentation. Originally from a micro-blog Han Han, causing users wantonly sought after. Then Wang Shi quoted Barton's words micro-blog tribute to Chu Shijian: "the measure of a man's success, not his climb to the top of the height, but he fell to the bottom rebound", for a time, users crazy forwarding.

\section{(4) Pay attention to brand building}

Chu orange is different from other ordinary fruit packing, Chu orange characteristics unique packaging, the packaging has a two-dimensional code, not only security, can also facilitate the consumers two orders. Not only that, the packaging will be printed on the "micro orange to greet the main" cute fashion advertisement, have a deep impression and appeal for the 90 young consumer groups.

4. The successful innovation of agricultural products marketing strategy

\section{1 determine the target consumer groups}

Willing to use the Internet to buy agricultural products, consumers are bound to have a necessary level of understanding of the network, that is, well-educated, consumer style, trendy groups, this group of people tend to have a strong purchasing power.

\subsection{The effective use of network marketing means}

Face of the target consumer groups, information should be accurate to find ways and means of information dissemination of promotional products, such as WeChat can use the public number, subscription number, search engines and other means, the possibility of more consumers understand the product information, increase the degree of attention, and marketing activities and consumers effectively carry out good interaction between consumers, enhance and the product brand activity and stickiness.

\subsection{Enhance brand awareness}

Because of the large quantity of producers and the scattered distribution of agricultural products, producers often ignore the brand value of agricultural products. Without brands, they sometimes push down product prices, or even lack product awareness, and make it difficult to sell agricultural products. Therefore, operators are concerned about product quality accidents, should also strengthen the brand concept, through product packaging, advertising display products, fashion personality characteristics, innovative way in sales in order to achieve better sales.

\section{Conclusions}

To sum up, only by locking the target consumer groups, carrying out effective marketing strategies and building a reasonable brand culture, can we effectively promote the sustainable development of agricultural products in network marketing activities.

\section{Acknowledgement}

This work was supported by the grants from Hubei Provincial Collaborative Innovation Centre of Agricultural E-Commerce (under Construction ) (Wuhan Donghu university research [2015] No. 11 Document)。

\section{References}

[1] Wood. "Chu orange" a successful example of Yantai fruit fruit marketing [J].2014.1

[2] Li Bing, Zhang Yueying. Study on green marketing strategy of agricultural products. China market, [J].2013 (9): 16-17

[3] Hu Yongzhou. Constructing "Internet + agriculture" only the production mode of [J]. (modern management), only 2015.9 (7): 46-48

[4] Xia Gang, Pan Yang Fu. Research on the development model of network marketing channel of agricultural products [J]. e-commerce, 2012, (9): 7577

[5] Liu Meilian, Li Zhicheng. Research on consumer behavior in ecommerce environment [J]. China management science.2002. (6).

[6] Li Wenlian, Xia. Innovation of business model based on "big data" [J]. China industrial experience, 2013 (5): 83-95.

[7] Huang Shengmin, Liu Shan. Deconstruction and reconstruction of marketing system under the background of "big data" [J] modern communication: Journal of Communication University of China, 2013 (11): 13-20.

[8] Wang Daiqiang, Tang Renmin. Consumer behavior analysis based on a large data application architecture [J]. microcomputer and application.2014. (20): 50-53. 